\title{
Capsule Endoscopy Examination-Preliminary Review by a Nurse
}

\author{
YARON NIV, MD and GALIA NIV, MSc, RN
}

\begin{abstract}
Capsule endoscopy (CE) has been recommended as the method of choice for diagnostic endoscopy of the small bowel. An experienced nurse, after proper training, may contribute to the endoscopy procedures as previously described for sigmoidoscopy. The aim of this study was to evaluate the ability of an experienced gastroenterology nurse to prepare CE records for physician interpretation, by detecting abnormal thumbnails. A prospective, observational design was used. Fifty CE videos were preread by a specially trained gastroenterology nurse who thumbnailed the abnormalities detected for interpretation by the gastroenterologist. The nurse's description of the lesions and the calculated gastric and bowel transit times were compared to the interpretation of the videos made directly by the gastroenterologist (gold standard). The primary end point of the study was the quality of the nurse's pathology findings; the secondary end point was the cost effectiveness of this practice. There was complete agreement between the nurse and gastroenterologist for all 12 cases interpreted as normal by the gastroenterologist. In the remaining 38 cases, the nurse created 130 thumbnail selections and the physician, 99. Complete interobserver agreement was achieved for 93 of the 96 lesions categorized as "significant" by the physician (96.9\%). After all relevant variables were taken into account, this approach saved $\$ 324$ per CE examination. The use of nurse practitioner to preread CE videos and prepare thumbnail selections for further assessment by the gastroenterologist appears to be safe, reliable, and cost effective.
\end{abstract}

KEY WORDS: M2A; capsule endoscopy; endoscopy; enteroscopy; small bowel.

Recent studies recommending video capsule endoscopy (CE) as the method of choice for small bowel diagnostic endoscopy have led to its growing application in medical practice (1-4). At present, however, the extensive use of $\mathrm{CE}$ is limited by its high cost. Furthermore, as with any new technique, its proper implementation involves experience and a learning curve to minimize errors in interpretation. Previous studies of conventional endoscopy demonstrated variability in findings and interpretations among gastroenterologists (5-9), as well as between gastroenterologists and nurses (10-13). Most of the differences

\footnotetext{
Manuscript received December 29, 2004; accepted March 2, 2005.

From the Department of Gastroenterology, Rabin Medical Center, Beilinson Campus, Petach Tikva, and Sackler Faculty of Medicine, Tel Aviv University, Israel.

Address for reprint requests: Professor Yaron Niv, Department of Gastroenterology, Rabin Medical Center, Beilinson Campus, Petach Tikva 49100, Israel; nivyaron@013.net.il.
}

were associated with level of experience and borderline results $(8,9)$. There was a high level of agreement for clear and well-known findings, such as polyps and ulcers, and a low level for indeterminate lesions such as irregular "Z-lines."

Levinthal et al. (12) in a small study of 20 capsule videos, found that goal results were achieved when the capsule results were first read by a trained gastroenterology nurse who demarcated the areas of suspected pathology for further assessment by the physician. This strategy saved time and money without compromising the quality of the examination. It is supported by a wealth of evidence in the literature that gastroenterology nurses can efficiently interpret other types of endoscopic data (10-12).

The aim of the present study was to evaluate the ability of an experienced gastroenterology nurse to pinpoint abnormal findings and to prepare $\mathrm{CE}$ records for physician 
interpretation. The cost effectiveness of this method was calculated as well.

\section{METHOD}

A prospective observational study was performed to compare the CE findings of a gastroenterology nurse (G.N.) with 20 years' experience with those of an expert gastroenterologist (Y.N.). Prior to the study, the nurse was trained to read the CE video in 15 procedures. For purposes of the present study, each review provided the following information: capsule transit times of the stomach and small bowel, selection of thumbnails of abnormal images, and a brief description of the lesions. Capsule transit times and lesion locations were computed by RAPID reader software (Given Imaging, Yokneam, Israel). Each reviewer was blinded to the interpretation of the other. All lesions detected were classified as either significant, with potential effect on patient outcome (such as angiodysplasia, tumor, ulcer, flat mucosa, or capsule retention) or minor (such as redness or small isolated erosion).

Our primary end point was the quality of the nurse's pathology findings compared with the physician's. The results were compared in a face-to-face session. Missed lesions were discussed and classified, and decisions were made by consensus. The physician's interpretation was taken as the gold standard. In practice, the procedure should start with the nurse's interpretation. Our secondary end point was the cost effectiveness of the precedent thumbnail selection by the nurse. To calculate cost effectiveness, the following parameters were taken into account:

a. Cost of 1 hour of physician's time;

b. Cost of 1 hour of nurse's time;

c. Mean time of interpretation by the experienced physician;

d. Time (by the physician) needed to write up the report;

e. Time to interpret pathology findings by the experienced nurse; and

f. Average time to interpret the thumbnail selection(s) of the nurse by the experienced physician.

The formula for physician-only interpretation was as follows:

$$
(\mathrm{c}+\mathrm{d}) \times \mathrm{a}
$$

The formula for nurse's thumbnail selection procedure was as follows:

$$
(b \times e)+(d+f) \times a
$$

\section{RESULTS}

The demographic and clinical data of the patients are shown in Table 1, and the interpretations of the physician are shown in Table 2. There was complete agreement between the gastroenterologist and the nurse in all 12 cases interpreted as normal by the physician. In the remaining 38 cases, the nurse created 130 thumbnail selections and the physician created 99 . There was a complete agreement between the 2 reviewers for 93 of the 96 lesions defined as significant by the physician (96.9\%). The nurse missed 3 significant lesions in 3 patients: suspected short Barrett's esophagus in 1 and flat mucosa in the duodenum in 2 . The
TABle 1. BaCKGround Data of 50 Patients UNDERGOING CE

\begin{tabular}{lc}
\hline Age $(\mathrm{y})$ & \\
Mean \pm STD & $51 \pm 21$ \\
Range & $18-90$ \\
Gender & \\
Male & $29(58 \%)$ \\
Female & $21(42 \%)$ \\
Other investigations & \\
Colonoscopy & $39(78 \%)$ \\
Gastroscopy & $35(70 \%)$ \\
Small bowel x-ray & $22(40 \%)$ \\
Computed tomography & $13(26 \%)$ \\
Enteroscopy & $1(2 \%)$ \\
Indications & \\
Iron-deficiency anemia & $27(54 \%)$ \\
Abdominal pain & $10(20 \%)$ \\
Crohn's disease & $7(14 \%)$ \\
Celiac disease & $3(6 \%)$ \\
Lymphoma & $2(4 \%)$ \\
S/P small bowel transplantation & $1(2 \%)$ \\
\hline
\end{tabular}

physician missed 4 significant lesions in 3 patients: clot in the gastric mucosa, suspected short Barrett's esophagus, ileal aphthous lesions, and ileal polyp. Eleven minor lesions were found, 3 by the physician and 8 by the nurse. In 6 of these patients, there was agreement regarding a significant lesion. The mean gastric and small bowel transit times computed by the nurse were 26 and 304 minutes, respectively, and by the gastroenterologist, 26 and 318 minutes, respectively. The cecum was identified in 44 cases by the nurse and in 46 cases by the gastroenterologist (Table 3).

The mean time required to read the CE scan was $59 \pm$ 17 minutes for the physician and $100 \pm 13$ minutes for the nurse. The first 20 recordings read by the nurse took longer (mean $120 \pm 8$ minutes). The mean time needed by the physician to read the thumbnail selections of the nurse was $10 \pm 3$ minutes per patient.

The costs of interpretation by the physician and nurse are shown in Table 4. The total cost for the standard

\begin{tabular}{lc}
$\begin{array}{l}\text { TABLE 2. CAPSUlE VIDEO INTERPRETATIONS } \\
\text { BY THE PHYSICIAN IN 50 PATIENTS }\end{array}$ \\
\hline & $\mathrm{N}(\%)$ \\
\hline & $15(30)$ \\
Esophageal or gastric findings & $7(14)$ \\
Angiectasis & $6(12)$ \\
Ileal ulcers & $6(12)$ \\
Ileal nodular mucosa & $5(10)$ \\
Ileal polyp & $5(10)$ \\
Small bowel bleeding & $4(8)$ \\
Flat mucosa & $2(4)$ \\
Capsule retention & $2(4)$ \\
Lymphoma & $1(2)$ \\
Meckel's diverticulum & $12(24)$ \\
Normal &
\end{tabular}

Digestive Diseases and Sciences, Vol. 50, No. 11 (November 2005) 
TABle 3. Comparison of CAPSUle Results BetweEn ObServers $(n=50)$

Significant lesions detected by physician and missed by nurse Minor lesions detected by physician and missed by nurse Mean gastric transit time (min) demonstrated by physician Mean gastric transit time ( $\mathrm{min}$ ) demonstrated by nurse Mean small bowel transit time (min) demonstrated by physician Mean small bowel transit time ( $\mathrm{min}$ ) demonstrated by nurse Cecum demonstration by physician (patients)

Cecum demonstration by nurse (patients)

practice (physician-only) was $\$ 573$ and for the new method, \$249, for a savings of $\$ 324$ for each CE examination.

\section{DISCUSSION}

Nurse-practitioners have achieved recognition in many primary, secondary, and tertiary health care facilities (1417). The results of our study support this practice. We found that a trained nurse can reliably and consistently identify lesions on $\mathrm{CE}$ video recordings, leaving the physician more time for assessment and treatment planning. These findings expand the study of Levinthal et al. (12).

In CE, like for other endoscopy procedures, the learning curve and experience have an important impact on accuracy. Many studies of physician interobserver agreement demonstrate a wide range of deviation (6-9). The main predictive factors for agreement were observer experience and type of findings. The longer the experience and prevalent the finding, the better the agreement (5-9). The nurse in this study missed only 3 significant lesions in 3 patients: 1 was an incidental esophageal finding (CE has not been design for esophageal pathology evaluation), and 2 were flat mucosa (a rare finding that requires lot of experience to diagnose). With time, nurse-physician teams would develop improved methods of communication and performance, yielding more accurate test results.

Our calculations suggest that training nurse practitioners in first-pass interpretation of CE is cost efficient and

Table 4. Cost of CAPsule Reading

\begin{tabular}{lc}
\hline Physician hour cost & $\$ 500(8.3$ per minute $)$ \\
Nurse hour cost & $\$ 50(0.83$ per minute $)$ \\
$\begin{array}{l}\text { Average interpretation time by an } \\
\text { experienced physician }\end{array}$ & $59 \pm 17$ min \\
$\begin{array}{l}\text { Average length of time for physician } \\
\text { writing the report }\end{array}$ & $10 \pm 4 \mathrm{~min}$ \\
$\begin{array}{l}\text { Average pathology findings time by an } \\
\text { experienced nurse }\end{array}$ & $100 \pm 13 \mathrm{~min}$ \\
$\begin{array}{l}\text { Average time of interpretation } \\
\text { thumbnails by an experienced } \\
\text { physician }\end{array}$ & $10 \pm 5 \mathrm{~min}$ \\
\hline
\end{tabular}

Policy $\mathrm{I}=(59+10) 8.3=\$ 573$.

Policy II $=(100 \times 0.83)+(10+10) 8.3=\$ 249$. cost effective; our new policy can save $57 \%$ of the present cost of the examination, without compromising the quality of care. Our approach may expand the use of this expensive procedure.

In summary, the introduction of a new policy wherein a nurse practitioner prereads capsule endoscopies, allowing the gastroenterologist to view only the thumbnailed abnormalities detected, could improve the accuracy of the test and save the health system considerable costs. Further studies with larger samples are needed to confirm these findings.

\section{REFERENCES}

1. Costamagna G, Shah SK, Riccioni ME, et al:: A prospective trial comparing small bowel radiographs and video capsule endoscopy for suspected small bowel disease. Gastroenterology 123:999-1005, 2002

2. Goldgarb NI, Philips A, Conn M, Lewis BS, Nash DB: Economic and health outcomes of capsule endoscopy: Opportunities for improved management of the diagnostic process for obscure gastrointestinal bleeding. Disease Management 3:123-135, 2002

3. Saurin JC, Delvaux M, Gaudin JL, et al.: Diagnostic value of endoscopic capsule in patients with obscure digestive bleeding: Blinded comparison with video push-enteroscopy. Endoscopy 35:576-584, 2003

4. Appleyard M, Fireman Z, Glukhovsky A, et al.: A randomized trial comparing wireless capsule endoscopy with push enteroscopy for the detection of small-bowel lesions. Gastroenterology 119:14311438, 2001

5. Bour B, Person B, Cales $\mathrm{P}$, et al.: Interobserver agreement on endoscopic diagnosis of bleeding peptic ulcers. Gastrointest Endosc 46:27-32, 1997

6. Kusano M, Ino K, Yamada T, et al:: Interobserver and intraobserver variation in endoscopic assessment of GERD using the "Los Angeles" classification. Gastrointest Endosc 49:700-704, 1999

7. Smedh K, Olaison G, Jonsson KA, Johansson KE, Skullman S, Hallbook O: Interobserver variation of colonoileoscopic findings in Crohn's disease. Scand J Gastroenterol 30:81-86, 1995

8. Armstrong D, Bennett JR, Blum AL, et al:: The endoscopic assessment of esophagitis: A progress report on observer agreement. Gastroenterology 111:85-92, 1996

9. Wallner B, Sylvan A, Janunger KGL: Endoscopic assessment of the "Z-line" (squamocolumnar junction) appearance: Reproducibility of the ZAP classification among endoscopists. Gastrointest Endosc 55:65-69, 2002

10. Shapero TF, Alexander PE, Hoover J, Burgis E, Schabas R: Colorectal cancer screening: Video-reviewed flexible sigmoidoscopy by nurse endoscopists-A Canadian community-based perspective. Can J Gastroenterol 15:441-445, 2001

11. Goodfellow PB, Fretwell IA, Simms JM: Nurse endoscopy in a district general hospital. Ann R Coll Surg Engl 85:181-184, 2003

12. Levinthal GN, Burke CA, Santisi JM: The accuracy of an endoscopy nurse in interpreting capsule endoscopy. Am J Gastroenterol 98:2669-2671, 2003

13. Schoenfeld P, Lipscomb S, Crook J, et al.: Accuracy of polyp detection by gastroenterologists and nurse endoscopists during flexible 
sigmoidoscopy: A randomized trial. Gastroenterology 117:312318, 1999

14. Lewis BS, Swain P: Capsule endoscopy in the evaluation of patients with suspected small intestinal bleeding: Results of a pilot study. Gastrointest Endosc 56:349-353, 2002
15. Wilson D: Nurse practitioners: The early years (1965-1974). Nurse Pract 19:26-28, 1994

16. Froerer R: The nurse endoscopist: Reality or fiction? Gastroenterol Nurs 21:15-20, 1998

17. Sprout J: Nurse endoscopist training: The next step. Gastroenterol Nurs 23:111-115, 2000 